\title{
Keragaman kasus patologi forensik di RSUP Prof. Dr. R. D. Kandou Manado dari sudut pandang SKDI 2012 periode Juli 2015-Juni 2016
}

\author{
${ }^{1}$ Charity C. Tololiu \\ ${ }^{2}$ Erwin G. Kristanto \\ ${ }^{2}$ Nolla T. S. Mallo \\ ${ }^{1}$ Kandidat Skripsi Fakultas Kedokteran Universitas Sam Ratulangi Manado \\ ${ }^{2}$ Bagian Ilmu Kedokteran Forensik dan Medikolegal Fakultas Kedokteran \\ Universitas Sam Ratulangi Manado \\ Email: charityyct@gmail.com
}

\begin{abstract}
Forensic pathology is a study that focuses on determination of death causes by examining the corpse, especially for investigation of criminal cases and civil law cases. Knowledge and skills are needed for a doctor to get an accurate result of examination. Therefore, the general practicioners are required to master all the level of competence by the National Standard Competencies of Indonesian Medical Doctors 2012 (Standar Kompetensi Dokter Indonesia/SKDI). This study refered to Prof. Dr. R. D. Kandou Hospital as the main educational hospital for Medical Faculty of Sam Ratulangi University and also a tertiary health facility. This study was aimed to determine the diversity of cases in the Department of Forensic Pathology at Prof. Dr. R. D. Kandou Hospital from the viewpoint of National Standard Competencies of Indonesian Medical Doctors 2012 (Standar Kompetensi Dokter Indonesia/SKDI). This was a descriptive retrospective study. The result showed that the diversity of cases at Department of Pathology Forensic was 78\% which was sufficient for standard competency requirements. Conclusion: Overall, Prof. Dr. R. D. Kandou Hospital is still eligible as the main educational hospital of Medical Faculty of Sam Ratulangi University. It is suggested to prolong the period of study in Forensic Department to increase the number of cases as well as to support the study with medical videos in order to increase the knowledge about the level 2 - competency cases.
\end{abstract}

Keywords: forensic pathology, physician competence, SKDI 2012

\begin{abstract}
Abstrak: Patologi Forensik adalah ilmu yang berkaitan dengan penentuan penyebab kematian melalui pemeriksaan pada jenazah, dilakukan terutama untuk membantu investigasi kasus kejahatan atau kasus perdata. Ilmu dan ketrampilan seorang dokter dibutuhkan agar hasil pemeriksaan akurat. Dokter umum diwajibkan menguasai seluruh tingkat kompetensi dalam buku Standar Kompetensi Dokter Indonesia 2012. Penelitian merujuk pada RSUP Prof. Dr. R. D Kandou sebab rumah sakit tersebut merupakan faskes tersier yang juga merupakan rumah sakit pendidikan utama Fakultas Kedokteran UNSRAT. Penelitian ini bertujuan untuk mengetahui keragaman kasus Patologi Forensik di RSUP Prof. Dr. R. D. Kandou Manado dari sudut pandang SKDI 2012 periode Juli 2015 - Juni 2016. Jenis penelitian ialah deskriptif retrospektif. Hasil penelitian memperlihatkan bahwa $78 \%$ keragaman kasus di bagian Forensik mencukupi untuk kebutuhan standar akreditasi. Simpulan: Secara keseluruhan RSUP Prof. Dr. R. D. Kandou masih layak sebagai rumah sakit pendidikan utama Fakultas Kedokteran Universitas Sam Ratulangi. Disarankan memperpanjang masa studi di Bagian Forensik agar dapat meningkatkan jumlah kasus dan pembelajaran dengan video medis dalam meningkatkan pengetahuan tentang kasus yang memiliki tingkat kompetensi 2.
\end{abstract}

Kata kunci: patologi forensik, kompetensi dokter, SKDI 2012 
Patologi forensik adalah cabang ilmu kedokteran yang menerapkan ilmu pengetahuan dan teknologi kedokteran pada pemeriksaan jenazah dan segala hal yang berhubungan dengan kematian guna kepentingan peradilan. ${ }^{1}$ Patologi forensik merupakan salah satu cabang patologi yang berkaitan dengan penentuan penyebab kematian berdasarkan pemeriksaan pada mayat (autopsi). ${ }^{2}$

Pemeriksaan jenazah didahului dengan pemeriksaan luar tanpa melakukan tindakan invasif, meliputi pemeriksaan bungkus jenazah, pakaian satu per satu atau lapis demi lapis, deskripsi rinci seluruh bagian tubuhnya dan pemeriksaan perlukaan atau cedera. ${ }^{3}$ Tujuan pemeriksaan ini ialah untuk menentukan identitas mayat dan menentukan pola cedera dengan mengidentifikasi adanya luka atau tanda-tanda kekerasan, tanda-tanda tenggelam atau keracunan, serta mencari kelainan lainnya dan tanda-tanda kematian sekunder yang mungkin berkaitan dengan peristiwa kematian korban.

Dalam kasus forensik, penyebab kematian hanya dapat ditentukan berdasarkan pemeriksaan dalam (autopsi atau bedah jenazah). ${ }^{4} \quad$ Autopsi adalah pemeriksaan medis terhadap mayat dengan membuka rongga kepala, leher, dada, perut dan panggul serta bagian tubuh lain bila diperlukan, disertai dengan pemeriksaan jaringan dan organ tubuh didalamnya, baik secara fisik maupun dengan dukungan pemeriksaan laboratorium. ${ }^{3}$ Dalam KUHAP pasal 179 disebutkan bahwa dokter atau dokter ahli Kedokteran Kehakiman (forensik) jika diminta, wajib memberikan keterangan demi keadilan. Oleh sebab itu, pemeriksaan kedokteran forensik tidak boleh asal-asalan, karena hasilnya nanti akan digunakan sebagai keterangan ahli untuk peristiwa yang diduga tindak pidana. Untuk mendapatkan hasil yang akurat, dokter yang berkompeten wajib memiliki ilmu dan ketrampilan.

Kompetensi diperlukan sebagai syarat untuk dianggap mampu oleh masyarakat dalam melaksanakan tugas di bidang pekerjaan tertentu. ${ }^{5}$ Dalam kedokteran, telah disusun suatu buku acuan standar kompetensi untuk dokter umum yang bersifat nasional, yaitu Standar Kompetensi Dokter Indonesia (SKDI) yang merupakan sebuah perangkat penyetara mutu pendidikan dokter primer di Indonesia, dan juga menjadi acuan untuk pengembangan uji kompetensi dokter yang bersifat nasional. Dalam SKDI, terdapat tabel-tabel untuk masalah kesehatan individu dan masyarakat, daftar penyakit serta ketrampilan klinis dengan tingkat kompetensinya, khususnya untuk bagian Ilmu Kedokteran Forensik dan Medikolegal. Tingkat kompetensi pada bagian ini yang dominan ialah tingkat kompetensi 2, 3A, 3B, dan 4A. ${ }^{6}$

Sesuai dengan SK Menteri nomor 098/Menkes/SK/III/2014, RSUP Prof. Dr. R. D Kandou telah ditetapkan sebagai rumah sakit pendidikan utama Fakultas Kedokteran Universitas Sam Ratulangi. RSUP Prof. Dr. R. D. Kandou juga sudah terakreditasi, baik sebagai rumah sakit pendidikan maupun sebagai rumah sakit pelayanan. Sebagai rumah sakit pelayanan, RSUP Prof. Dr. R. D. Kandou ini tergolong tipe A yang terakreditasi paripurna. Harus dipahami bahwa RSUP Prof. Dr. R. D. Kandou ini merupakan rumah sakit institusi pelayanan kesehatan tersier. Jadi, tentu saja perlu dikaji apakah kasusnya cukup dan cocok untuk konsumsi pendidikan profesi dokter, khususnya di bagian Forensik.

Penelitian ini bertujuan untuk mengkaji informasi keragaman kasus patologi forensik yang ada di RSUP Prof. Dr. R. D. Kandou Manado selama periode Juli 2015 Juni 2016 dan untuk mengetahui apakah keragaman kasus patologi forensik di RSUP Prof. Dr. R. D. Kandou Manado sudah dapat memenuhi kebutuhan SKDI untuk dokter umum.

\section{METODE PENELITIAN}

Jenis penelitian ini ialah deskriptif retrospektif dengan desain potong lintang menggunakan visum hasil pemeriksaan mayat di Bagian Forensik RSUP. Prof. Dr. R. D. Kandou Manado. Pengambilan sampel menggunakan metode total sampling dengan kriteria inklusi yaitu seluruh data hasil pemeriksaan jenazah yang lengkap dan 
kriteria eksklusi yaitu data yang bukan pada periode Juni 2015-Juli 2016 dan yang kurang lengkap.

Definisi operasional yang digunakan yaitu: Angka kejadian (jumlah kasus patologi forensik yang masuk di RSUP Prof. Dr. R. D. Kandou Manado periode Juli 2015-Juni 2016). Kasus patologi forensik ialah yang berhubungan dengan pemeriksaan mayat yang masuk di Bagian Forensik RSUP Prof. Dr. R. D. Kandou Manado: Kasus kematian yang tidak jelas, kasus dengan kekerasan tumpul, kekerasan tajam, trauma kimia, luka tembak, luka listrik dan petir, kasus barotrauma, trauma suhu, asfiksia, tenggelam, pembunuhan anak sendiri, pengguguran kandungan, keracunan, jenazah yang tidak teridentifikasi, dan bunuh diri.

Pemeriksaan jenazah ialah jumlah kasus patologi forensik yang dilakukan tindakan pemeriksaan kedokteran forensik. Periode KKM berlangsung selama \pm 2 minggu. Kasus mencukupi adalah jumlah kasus yang berjumlah paling sedikit 1 kasus selama periode KKM sedangkan kasus tidak mencukupi adalah tidak ditemukannya kasus selama periode KKM.

\section{HASIL PENELITIAN DAN BAHASAN Jumlah kasus patologi forensik secara keseluruhan di RSUP Prof. Dr. R. D. Kandou Manado}

Tabel 1 menunjukkan bahwa total jumlah kasus kematian yang masuk di bagian Forensik RSUP Prof. Dr. R. D. Kandou Manado selama periode Juli 2015Juli 2016 sebanyak 150 kasus, dan yang dilakukan pemeriksaan luar berjumlah 143 kasus sedangkan yang dilakukan pemeriksaan luar sekaligus pemeriksaan dalam sebanyak 57 kasus. Kasus batal/ditolak berjumlah 7 kasus. Untuk kasus-kasus dengan keterangan batal/ ditolak bukan berarti kasus-kasus itu tidak diperlukan dalam pembelajaran, sebaliknya dari kasus-kasus tersebut, para dokter muda dapat belajar bagaimana proses penanganan jika menemukan kasus yang batal dilakukan pemeriksaan kedokteran forensik. Tabel 1 juga memperlihatkan bahwa setiap bulan tersedia $\geq 2$ kasus, artinya kasus untuk setiap periode KKM mencukupi.

Tabel 1. Jumlah kasus patologi forensik menurut data di Bagian Forensik RSUP Prof. Dr. R. D. Kandou Manado periode Juli 2015 Juni 2016

\begin{tabular}{lcccc}
\hline \multirow{2}{*}{ Bulan } & Masuk & \multicolumn{2}{c}{ Diperiksa } & Batal/ \\
\cline { 3 - 4 } & & Luar & Dalam & ditolak \\
\hline Juli & 13 & 12 & 7 & 1 \\
Agustus & 10 & 9 & 5 & 1 \\
September & 15 & 15 & 7 & 0 \\
Oktober & 11 & 11 & 4 & 0 \\
November & 9 & 9 & 4 & 0 \\
Desember & 13 & 12 & 5 & 1 \\
Januari & 9 & 9 & 2 & 0 \\
Februari & 22 & 20 & 9 & 2 \\
Maret & 13 & 12 & 2 & 1 \\
April & 10 & 9 & 2 & 1 \\
Mei & 14 & 14 & 5 & 0 \\
Juni & 11 & 11 & 5 & 0 \\
Jumlah & 150 & 143 & 57 & 7 \\
\hline
\end{tabular}

\section{Jumlah kasus patologi forensik berdasarkan jenis kelamin}

Gambar 1 menunjukkan bahwa korban terbanyak yang masuk di Bagian Forensik RSUP Prof. Dr. R. D. Kandou Manado periode Juli 2015 - Juli 2016 ialah laki-laki (87\%). Peneliti mendapatkan bahwa sebagian besar kasus yang masuk di bagian Forensik di RSUP Prof. DR. R. D. Kandou Manado ialah kasus kecelakaan lalu lintas (KLL) dan trauma tajam.

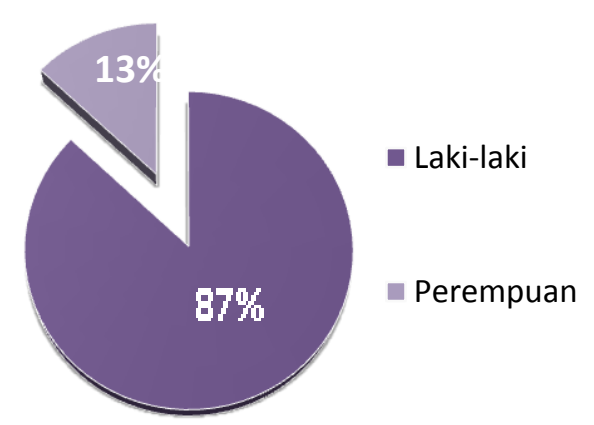

Gambar 1. Diagram lingkaran jumlah kasus patologi forensik berdasarkan jenis kelamin 
Hal ini sejalan dengan penelitian Singh $^{7}$ yakni korban terbanyak yang meninggal akibat KLL ialah laki-laki $(78,3 \%)$ dan Nerchan ${ }^{8}$ yakni korban terbanyak yang meninggal akibat kekerasan tajam ialah laki-laki $(88,9 \%)$.

Salah satu faktor yang mungkin memengaruhi ialah laki-laki sebagai kepala keluarga yang harus mencari nafkah di luar tempat tinggal, sehingga laki-laki lebih sering menggunakan jalan raya dalam berlalu lintas. Faktor lainnya ialah minuman keras/ alkohol. Sulawesi Utara merupakan provinsi dengan prevalensi mengonsumsi alkohol terbanyak di daerah perkotaan. Prevalensi minum alkohol pada laki-laki lebih dominan dibandingkan perempuan. ${ }^{9}$ Akibat dari pengaruh alkohol ini, maka pusat pengendalian diri seseorang akan tertekan, sehingga orang tersebut dapat menjadi lebih berani dan agresif, yang menyebabkan aksi ugal-ugalan di jalan raya. Dilaporkan bahwa sepertiga KLL disebabkan oleh pengemudi di bawah pengaruh alkohol. ${ }^{10}$ Penyalahgunaan alkohol ini pula dapat menyebabkan perilaku menyimpang seperti perkelahian dan tawuran ${ }^{11}$ sehingga kelompok laki-laki juga dominan menjadi korban kekerasan tajam.

\section{Jumlah kasus patologi forensik secara variatif di RSUP Prof. Dr. R. D. Kandou Manado}

Jumlah kasus patologi forensik secara variatif dapat dilihat pada Gambar 2. Hasil penelitian menunjukkan bahwa jumlah kasus terbanyak yang masuk di bagian Forensik RSUP Prof. Dr. R. D. Kandou Manado selama periode Juli 2015-Juni 2016 ialah kasus dengan trauma tumpul sebanyak 116 kasus (61\%). Kasus yang paling banyak ditemukan di Bagian Forensik RSUP Prof. Dr. R. D. Kandou ialah kecelakaan lalu lintas. Cara kejadian trauma karena sebab benda tumpul sering disebabkan oleh kecelakaan $^{12}$ sehingga hasil penelitian ini sejalan dengan penelitian Singh $^{7}$ yaitu angka kejadian terbanyak didapatkan pada kasus kecelakaan lalu lintas $(50,8 \%)$. Kasus kematian yang tidak jelas, kasus dengan trauma kimia, luka tembak, luka listrik dan petir, kasus barotrauma, dan kasus bunuh diri tidak mencukupi karena tidak didapatkan kasus selama periode Juli 2015Juni 2016 (Gambar 2).



Gambar 2. Grafik batang jumlah kasus berdasarkan masalah kesehatan individu dan masyarakat

Ganbar 3 memperlihatkan bahwa kasus penyebab kematian terbanyak yang masuk di Bagian Forensik RSUP Prof. Dr. R. D. Kandou Manado ialah kekerasan tumpul dengan 116 kasus (63\%) dan kekerasan tajam 46 kasus (25\%). Walaupun tingkat kompetensi 4A hanya kekerasan tumpul dan tajam, namun tidak berarti bahwa kasus-kasus lain dengan tingkat kompetensi 2 dan 3 tidak diperlukan untuk pembelajaran, sebab saat masa pembelajaran selesai, dokter-dokter muda akan ditempatkan di seluruh wilayah Indonesia, tidak terkecuali wilayah yang tidak memiliki rumah sakit yang memadai maupun dokter ahli, sehingga diperlukan pula ilmu dan ketrampilan untuk mampu menangani kasus-kasus tersebut. 


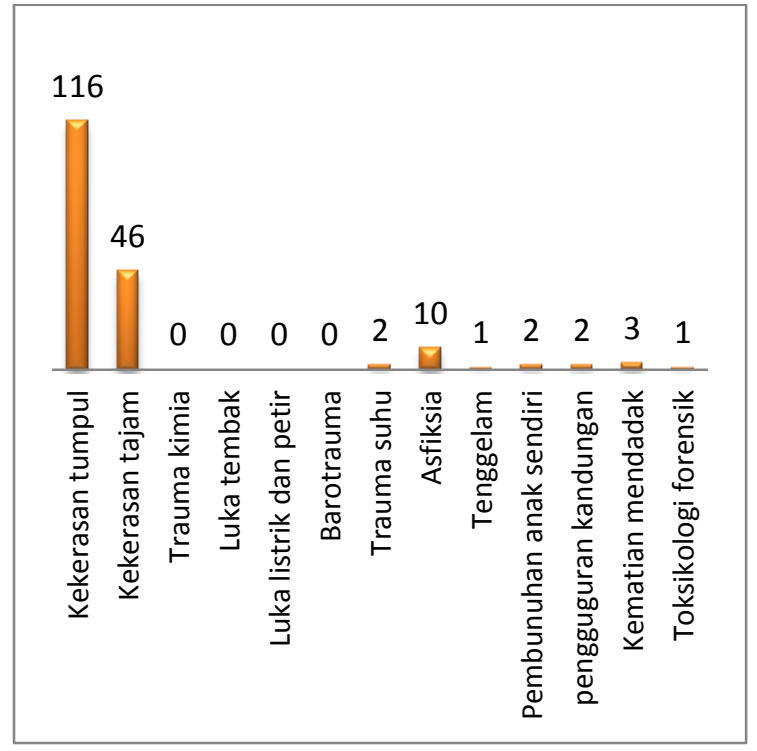

Gambar 3. Grafik batang jumlah kasus berdasarkan penyebab kematian

Gambar 4 memperlihatkan bahwa kasus untuk semua pemeriksaan mencukupi. Perlu diketahui bahwa setiap jenazah membutuhkan pemeriksaan yang berbeda-beda, artinya pemeriksaannya tidak harus sama dan tidak harus hanya satu pemeriksaan. Pemeriksaan harus sesuai dengan kasus kematian dan tanda-tanda kekerasan yang didapatkan pada jenazah.

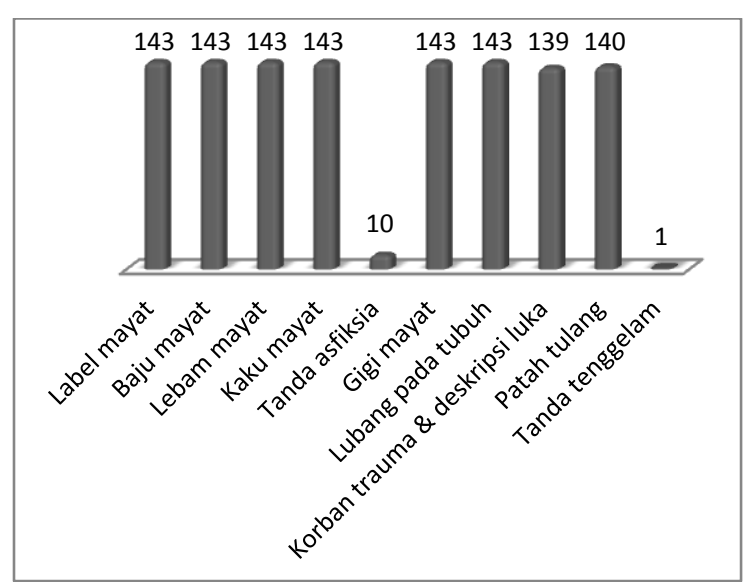

Gambar 4. Grafik batang jumlah kasus berdasarkan ketrampilan klinis teknik pemeriksaan pada korban mati

Semua pemeriksaan pada tabel diatas merupakan tingkat kompetensi 4A, dan walaupun pada tabel daftar penyebab kematian sebelumnya menyebutkan bahwa kasus asfiksia dan tenggelam hanya mempunyai tingkat kompetensi 3A, namun ketrampilan klinis untuk kedua kasus tersebut adalah tingkat kompetensi 4A yang sudah tentu seluruh teori teknik pemeriksaannya wajib dikuasai oleh dokter umum.

Gambar 5 menunjukkan bahwa kasus untuk semua pemeriksaan diatas mencukupi. Sama dengan tabel sebelumnya, pemeriksaan setiap jenazah bisa saja berbeda-beda dan lebih dari satu pemeriksaan. Semua pemeriksaan pada tabel di atas memiliki tingkat kompetensi 2 yang harus ditangani oleh dokter spesialis, sehingga sebenarnya jumlahnya tidak terlalu berpengaruh.

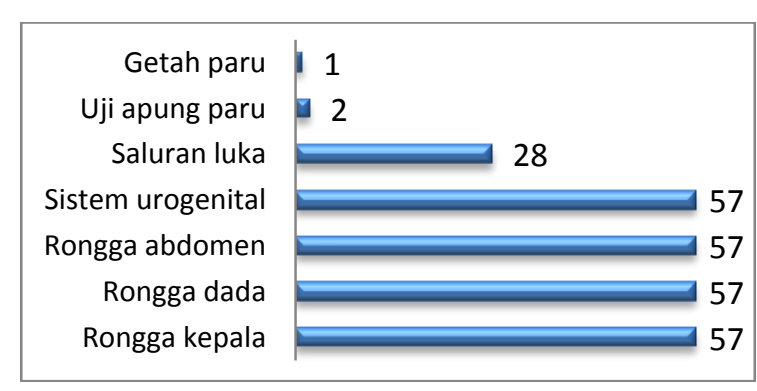

Gambar 5. Grafik batang jumlah kasus berdasarkan ketrampilan klinis teknik autopsi

\section{SIMPULAN}

Dari hasil penelitian mengenai keragaman kasus patologi forensik di RSUP Prof. Dr. R. D. Kandou Manado periode Juli 2015 - Juni 2016 berdasarkan sudut pandang SKDI 2012 diperoleh data bahwa secara keseluruhan RSUP Prof. Dr. R. D. Kandou masih layak sebagai rumah sakit pendidikan utama Fakultas Kedokteran Universitas Sam Ratulangi.

\section{DAFTAR PUSTAKA}

1. Peraturan Kepala Kepolisian Negara RI No. 12 Tahun 2011 Tentang Kedokteran Kepolisian. Available from: https://www.scribd.com/mobile/doc/11 8952108/Perkap-Nomor-12-TtgKedokteran-Kepolisian

2. Marbun R, Bram D, Isnaeni Y, Nusya A. Kamus Hukum Lengkap (1st ed). Jakarta: Visimedia, 2012; p. 218.

3. Sampurna B, Samsu Z, Tjetjep DS. Peranan Ilmu Forensik dalam Penegakan Hukum; sebuah pengantar 
(1st ed). Jakarta: Fakultas Kedokteran Univeristas Indonesia, 2008; p. 91.

4. Dudley HAF, Eckersley JRT, PatersonBrown S. Pedoman Tindakan Praktis Medik dan Bedah. Jakarta: EGC, 2000; p. 76.

5. Keputusan Menteri Pendidikan Nasional RI No. 045/U/2002. Available from: http://www.fti.itb.ac.id/wpcontent/uploads/2015/06/Kepmendikna s-045-Tahun-2002-tentang-KurikulumInti-PT.pdf

6. Standar Kompetensi Dokter Indonesia (2nd ed). Jakarta: Konsil Kedokteran Indonesia, 2012; p. 27,57,83-4.

7. Singh SKA. Angka kejadian korban kecelakaan lalu lintas berdasarkan hasil pemeriksaan luar visum et repertum di RSUP Dr. Mohammad Hoesin Palembang tahun 2011-2013. MKS. 2015;42:107-9.
8. Nerchan E. Pola luka pada kematian akibat kekerasan tajam di bagian ilmu kedokteran forensik dan medikolegal RSUP Prof. DR. R. D. Kandou Manado periode 2013. eCl. 2015;3:640-5.

9. Suhardi. Preferensi peminum alkohol di Indonesia menurut RISKESDAS 2007. Buletin Penelitian Kesehatan. 2011;39(4):158-60.

10. Faot N. Kajian faktor predisposisi perilaku mengkonsumsi minuman keras pada mayarakat di Desa Oelpuah Kabupaten Kupang tahun 2010. MKM. 2010:5;1727.

11. Lomban KA. Permasalahan dan segi hukum tentang alkoholisme di Indonesia. Lex Crimen. 2014:3;142.

12. Satyo AC. Aspek medikolegal luka pada forensik klinik. Majalah Kedokteran Nusantara. 2006;4:431. 